\title{
CATRAL, DE LA HUERTA TRADICIONAL A LA HUERTA URBANIZADA. LA TRANSFORMACIÓN DEL PAISAJE AGRARIO EN EL BAJO SEGURA: DEL ANIMUS REGANDI AL ANIMUS AEDIFICANDI
}

\author{
Clara García-Mayor* \\ Gregorio Canales Martínez** \\ Universidad de Alicante
}

\section{RESUMEN}

El municipio de Catral es un ejemplo paradigmático en la Huerta histórica del Segura. Este territorio muestra las consecuencias del proceso de mutación del paisaje agrario debido a un cambio en el modelo socioeconómico, que utiliza el recurso suelo para implantar el uso turístico-residencial, incentivado desde la legislación urbanística y una laxitud administrativa en el control de la aplicación de la misma. Este caso de estudio ofrece un patrón de transformación que ha evolucionado desde el respeto al medio y conocimiento secular de las características del lugar de los primigenios asentamientos compactos, a una colonización dispersa, carente de estructura formal e integración sobre el espacio en el que se desarrolla.

Palabras clave: Catral, cambio paisajístico, regadío histórico, fragmentación Huerta, atomización urbano-industrial.

Catral, from the Traditional Huerta to the Urbanised Huerta.

The Transformation of the Bajo Segura Agricultural Landscape: from Animus Regandi to Animus Aedificandi

Recibido: 18 de diciembre de 2015

Devuelto para su revisión: 27 de mayo de 2016

Aceptado: 4 de julio de 2016

* Departamento de Edificación y Urbanismo. Universidad de Alicante. Apartado 99. 03080 ALICANTE (España).E-mail: magarma@ua.es

** Departamento de Geografía Humana. Universidad de Alicante. Apartado 99. 03080 ALICANTE (España). E-mail: gregorio.canales@ua.es 


\begin{abstract}
The municipality of Catral is a prime example of the historical Huerta of the Segura River. The process of transformation of agricultural landscape, resulting from changes in the socio-economic model, has had a significant impact on the landscape perception. To understand this transformation, it is important to consider that new touristic and residential use of land has been encouraged and supported by favorable town planning regulations and a certain degree of laxness in terms of compliance with urbanistic rules. This case study highlights a pattern reflecting a change from the earlier settlers, whose respect and understanding of the territorial environment is evident from their development of a fertile agricultural system from marshland, to the present-day residential developments that follow a suburban sprawl model, which lacks formal structure and landscape integration.
\end{abstract}

Keywords: Catral, Huerta, landscape transformation, landscape integration, landscape fragmentation, urban-industrial sprawl.

\title{
1. LA APARICIÓN DEL TURISMO LITORAL EN EL BAJO SEGURA
}

La comarca del Bajo Segura comprende el extremo meridional de la provincia de Alicante, toma su denominación del principal eje fluvial que atraviesa el territorio y que durante siglos posibilitó la aparición de un espacio agrícola intensivo -la Huerta de Orihuela- que, hasta mediados del siglo XX constituyó la principal fuente de riqueza de su economía. A partir de entonces se produce un cambio de modelo productivo vinculado al turismo, inicialmente en aquellos municipios con núcleos costeros, como Torrevieja y Guardamar del Segura que van a ser pioneros en introducir un proceso urbanístico de segundas residencias para su ocupación estival. Ambos contaban con una tradición vinculada a las vacaciones familiares, si bien con diferentes patrones de asentamiento en virtud de las redes de comunicación y del área de atracción que cada uno de ellos ejercía. El primero se vio beneficiado desde 1884 por la conexión ferroviaria del ramal que partía de la línea Alicante-Murcia, y que favoreció la movilidad entre Madrid y la costa sur alicantina; circunstancia que produjo un flujo de veraneantes procedentes del interior de la península, que junto con los oriundos de los municipios colindantes impulsó un rápido crecimiento del tejido urbano frente al mar. Por el contrario, el segundo permaneció vinculado a una demanda de carácter comarcal, que impulsó una dinámica de desarrollo inmobiliario de escala más reducida, generando un poblado marítimo a escasos metros del asentamiento principal.

En este contexto, será el Plan de Estabilización del ministro Alberto Ullastres el que posibilitó una apertura a los mercados internacionales, siendo precisamente el Decreto-Ley de Ordenación Económica de 21 de julio de 1959 el punto de inflexión en la política económica del régimen franquista para superar la etapa autárquica (1940-1959). Este hecho auspició la inversión extranjera en nuestro país, de la que el sector turístico fue uno de los máximos beneficiarios (Fernández Navarrete, 2005). El "desarrollismo" de la década de los años sesenta tuvo un claro reflejo en aquellos enclaves litorales del Bajo Segura que, a 
lo largo de treinta y siete kilómetros de costa, ofrecían mejores condiciones naturales para la actividad turística. Fue así como el municipio de Orihuela se incorpora a este proceso de expansión que originó la aparición de nuevas urbanizaciones de ocupación temporal. El fenómeno conocido como "turismo de masas" se hace realidad para Torrevieja a partir de 1965 (Vera Rebollo, 1984), punto de partida de un proceso continuado de ocupación intensiva del territorio, de carácter nodular, con acaparamiento de amplias extensiones de terreno (antiguas fincas de secano) por parte de determinadas empresas promotoras que, desde su posicionamiento en el mercado inmobiliario, han regulado implícitamente las ampliaciones de suelo (Casado Díaz, 1999), frecuentemente en connivencia con una administración permisiva, en la que las herramientas de planeamiento han sido el instrumento para la consolidación de este modelo.

El análisis de ocupación del territorio, evolucionado desde la agricultura al turismo como fuente de riqueza, se puede sintetizar en cuatro patrones que obedecen a estrategias de desarrollo diferentes: a) Guardamar del Segura responde a un esquema de crecimiento en mancha de aceite que termina fusionando al núcleo fundacional el dilatado asentamiento producido a lo largo de la costa; b) Torrevieja coloniza su municipio mediante una serie de urbanizaciones, dependientes del centro administrativo de la ciudad, en un principio desconectadas entre sí, pero con procesos propios de crecimiento que han acabado en conurbaciones de las áreas residenciales suburbanas mediante una red viaria radial; c) Orihuela, por el contrario, carece de núcleo rector en la propia costa, por lo que los procesos urbanísticos surgieron por la iniciativa privada de propietarios de fincas rústicas, que desembocó en una organización espacial polinuclear no jerarquizada; d) Por último, Pilar de la Horadada surgirá como municipio independiente de Orihuela en 1986 y constituye un exponente del dinamismo urbanístico propio de la zona, desarrollando una transformación híbrida que compagina el proceder de los dos primeros casos citados.

Los enclaves residenciales evolucionan desde las ubicaciones relacionadas directamente con el frente marítimo hacia posiciones más interiores, bien sobre oteros que mantienen la conexión visual con el mar, bien conformando una nueva oferta vinculada al campo de golf como objeto de atracción para el ocio, en un contexto de naturaleza reinventada. Estos núcleos han pasado de una ocupación vacacional temporal, a ser la vivienda habitual de una población creciente; donde la consolidación de la vocación turística heliotrópica, ha condicionado el modelo residencial dominante en la actualidad. Esta pauta de comportamiento reproduce, a pequeña escala, los procesos de suburbanización experimentados en las grandes metrópolis del mundo occidental, que siguen un proceso de dispersión que se ha tipificado en varias fases: en un primer estadio se traslada el uso, industrial o habitacional, como procesos conjuntos o independientes; a éste sigue la actividad comercial y de servicios complementarios; para terminar con la incorporación de la administración local. Orihuela ejemplifica magníficamente bien esta dinámica, que ha motivado la aparición de la demarcación denominada "Orihuela-costa" con una sede de servicios municipales descentralizados, sintomático del alto nivel de densidad demográfica y consolidación residencial (Canales y López, 2012).

El dinamismo del sector turístico y residencial se contrapone a la pérdida de competitividad agrícola del regadío tradicional, circunscrito al llano aluvial del Segura, que 
secularmente constituyó la fuente de riqueza de esta comarca y determinó la ubicación de los núcleos poblacionales. Éstos se situaron en los flancos montañosos que delimitan el valle y en los microrrelieves centrales, por encima del nivel de inundación, con una estrategia de crecimiento que no mermara la superficie productiva de la Huerta. De los veintisiete municipios que conforman el Bajo Segura, el $81 \%$ participa parcial o totalmente del terreno regado, y sitúan sus cabeceras municipales en las inmediaciones del mismo o en su interior. Lo que antaño condicionó la organización territorial, siendo la agricultura la que trabó el vínculo social, económico y medioambiental del terreno con sus habitantes, entra en una profunda crisis que favorece la mutación, en las últimas décadas, hacia otro modo productivo de consumo de suelo que introduce, de manera generalizada, el proceso especulativo inmobiliario como alternativa de negocio frente a los problemas que presenta la agricultura minifundista, en el escenario europeo actual.

\section{NUEVOS HÁBITATS EN EL REGADÍO HISTÓRICO}

La Huerta es el resultado de siglos de actuación humana sobre un territorio palustre y hostil para el asentamiento humano, en el que la supervivencia dependía tanto de los aprovechamientos tradicionales de la zona encharcada, como de la existencia del anillo montañoso que ciñe el llano aluvial y que posibilitó el poblamiento en cotas elevadas al abrigo de las inundaciones del río Segura y con mejores condiciones ambientales al quedar más libres de la incidencia de enfermedades contagiosas derivadas de las aguas estancadas. La geomorfología del valle ha condicionado la naturaleza indómita de este espacio, que junto con una climatología de temperaturas benignas contrastadas con grandes carencias pluviométricas, contribuyeron a que los pobladores implantaran un ingenioso sistema para hacer viable una de las áreas agrícolas más fértiles del sureste español, en cantidad de cosechas y variedad de cultivos. El proceso de transformación comprende la secuencia: desecación - riego - avenamiento, que es necesario repetir reiterativamente conforme progresa la expansión del regadío a costa del retroceso del humedal. La existencia de una capa de limos arcillosos en el subsuelo, a escasa profundidad, es la causante de la retención parcial del agua en la superficie; por ello, fue necesario desarrollar una red híbrida de aporte y drenaje de los caudales necesarios para el éxito de la agricultura.

Los cambios acaecidos llevaron parejo el retroceso de los aprovechamientos naturales que se daban en origen, como caza, pesca, pastos y recolección de plantas silvestres; junto con la migración de los pobladores a ubicaciones más bajas, próximas a los predios, con el fin de vigilar y mantener en perfectas condiciones el sistema hídrico creado. El descuido en estas labores acarreaba el retorno a la situación inicial, donde la voracidad de la naturaleza se imponía sobre el colonizado. Esta dicotomía histórica de un territorio en permanente mutación, se reproduce en la actualidad ante la crisis de la agricultura familiar. Los hábitats propios, a partir de los que se gestó la Huerta son tres: los suelos de almarjal, de carrizal y de saladar. Los primeros poseían un carácter pantanoso al ubicarse en las cotas más bajas del interior de la planicie; los segundos se desarrollaban en terrenos húmedos, con un nivel freático muy alto casi próximo a la superficie, por lo que en ellos prosperaba la vegetación de carrizos que le da nombre; los terceros, son las tierras salinas que permanecían a lo largo del año prácticamente 
secas y donde las altas temperaturas originaban la presencia de una costra blanquecina de cloruro sódico. Estos dominios fluctuaban a lo largo del año en virtud de las precipitaciones, de los aportes hídricos por los desbordamientos del río y la confluencia de ramblas, así como por el afloramiento de varios manantiales que contribuían a mantener el espacio encharcado (Canales y De Juanes, 2016).

Esta diversidad construye una relación ecológico-ambiental muy rica, cuyo retroceso abarca siglos de actividad humana. De los tres ecosistemas descritos, sólo el carrizal persiste en aquellas parcelas que no mantienen la producción, pues se ven invadidas de nuevo por la vegetación autóctona, caracterizada por su capacidad de dispersión, su persistencia y por ser muy competitiva en la pugna por el suelo, el agua y los nutrientes. La consecuencia directa es el deterioro de las estructuras agrarias -canalizaciones, parcelas y veredas, entre otros-, además de convertirse en refugio de plagas y enfermedades que afectan a los cultivos en explotación y transmiten una imagen negativa del paisaje. No hay que olvidar que la Huerta se construye a partir de la superposición de cuatro redes funcionales: las del agua (riego-avenamiento, materializadas con el sistema de acequias y azarbes respectivamente), las del recorrido (caminos), los asentamientos (población-hábitat rural) y las productivas (campos-cultivos). Estas capas indicadas de manera desagregada, están realmente cohesionadas y son interdependientes en su naturaleza y origen; de manera que configuran la clave de lectura de este territorio complejo en su constitución y variado en la diversidad de rendimientos que de él se obtenían.

Hasta mediados del siglo XX, toda la llanura presentaba una gran homogeneidad visual derivada de su organización espacial-funcional, donde la red del agua es determinante para la implantación del resto de elementos identitarios: así el denso entramado caminero acompaña en su distribución a los complejos sistemas de canalizaciones, sirviendo a su vez de espacio de acceso a las fincas, control de distribución de caudales y conservación de cauces, protección de la red hidráulica con el recrecimiento de las motas y, por último, marca el patrón de ocupación de las viviendas huertanas, bien concentrada en núcleos urbanos, bien dispersa en las inmediaciones del área cultivada, buscando una mejor eficacia del cuidado de las plantaciones. Frente a este modelo, contrasta la presencia de un hábitat diseminado que podemos agrupar en dos tipologías: el propiamente aislado, que se corresponde con la casa de labor sita en la explotación agraria, y las agrupaciones rectilíneas que conforman los característicos pueblos camineros que serpentean por la Huerta. Estos poblados-calle tienen su origen en la apropiación espontánea y consentida, tanto de los límites de antiguas cañadas o veredas, como en las márgenes de los canales, generando protección a la propia infraestructura e incluso cubriendo el cauce dando lugar a la tipología de casa-mota. Ambos procesos, pertenecientes a un contexto socioeconómico muy distinto al actual, dieron lugar a la extendida práctica de usurpación del dominio público, convertido en un espacio de oportunidad donde braceros y jornaleros pudieran levantar sus modestas viviendas de autoconstrucción (García y Canales, 2015).

El núcleo fundacional de Catral es un ejemplo de aldea-calle que sigue la traza rectora marcada por la Acequia Mayor de Callosa y el eje caminero que conectaba las barriadas de La Cruz con la de Santa Águeda, apéndices periféricos en la trama urbana actual. La fisionomía alargada de este conjunto responde a los condicionantes de las redes de agua y viaria, todavía identificable pese a los crecimientos residenciales recientes. El desa- 
Figura 1

SANTA ÁGUEDA - EL SANTIEL, UN EJEMPLO DE PUEBLO LINEAL

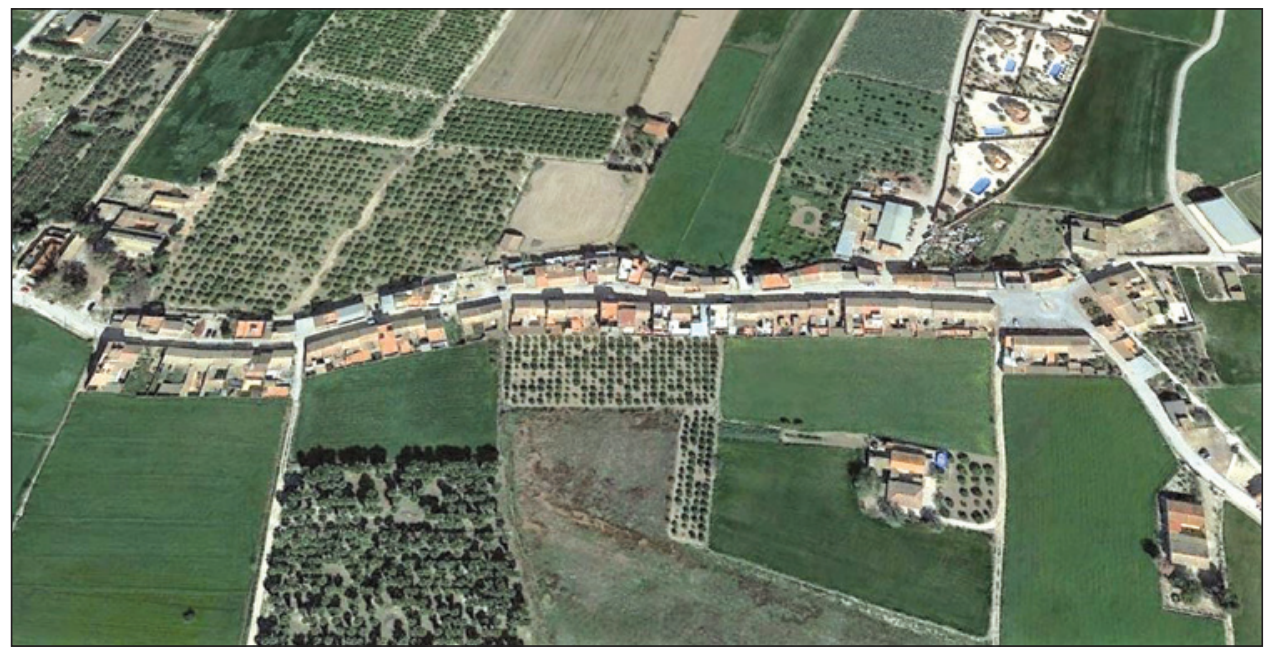

Fuente: Google Earth (marzo, 2015).

rrollo de este poblamiento, con tres kilómetros de longitud, se puede analizar en tramos de extensión similar: el oriental correspondiente a la Calle de Santa Águeda, topónimo que toma de la ermita donde finaliza en confluencia con el poblado de El Santiel, que mantiene igualmente una morfología lineal; el central que aglutina los servicios al reunir la Iglesia de Los Santos Juanes y el Ayuntamiento; y el occidental articulado a lo largo de la Calle de La Cruz. La relación espacial y funcional del espacio urbano con respecto a los terrenos agrícolas circundantes responde a un mismo patrón de asentamiento, caracterizado por la ubicación de las viviendas en el microrrelieve provocada por la mota del canal de riego junto al camino de acceso.

Analizando la topografía de la zona se observa que permanece por debajo de la isohipsa de 10 metros, es decir, estamos en uno de los puntos más bajos de la planicie. Si reparamos en las secciones transversales de cada unidad, se comprueba la existencia de un desnivel entre las casas y los huertos que oscila de uno a dos metros de altitud en cotas relativas. Una distancia mínima que proporcionaba seguridad frente a las periódicas inundaciones del río, a la vez que favorece la distribución de agua por gravedad siguiendo las líneas de máxima pendiente. Esta disposición se repite simétricamente a ambos lados del eje: al norte el desnivel se prolonga hasta el Azarbe de la Partición, que a su vez ejerce de canal de riego para parcelas ubicadas aguas abajo en el antiguo municipio de San Felipe Neri (hoy Crevillente); mientras que al sur los drenajes se dirigen al Azarbe de la Palmera, que transforma en cola su función a la de acequia para regar tierras en Catral. Esta aproximación al medio es una muestra de la complejidad de todo el sistema organizativo en su conjunto, prueba evidente de la secular adaptación del hombre a su entorno de vida, a través de la que se desarrolla una cultura territorial vinculada al agua. 


\section{Figura 2 \\ DISPOSICIÓN TOPOGRÁFICA DEL HÁBITAT LINEAL}
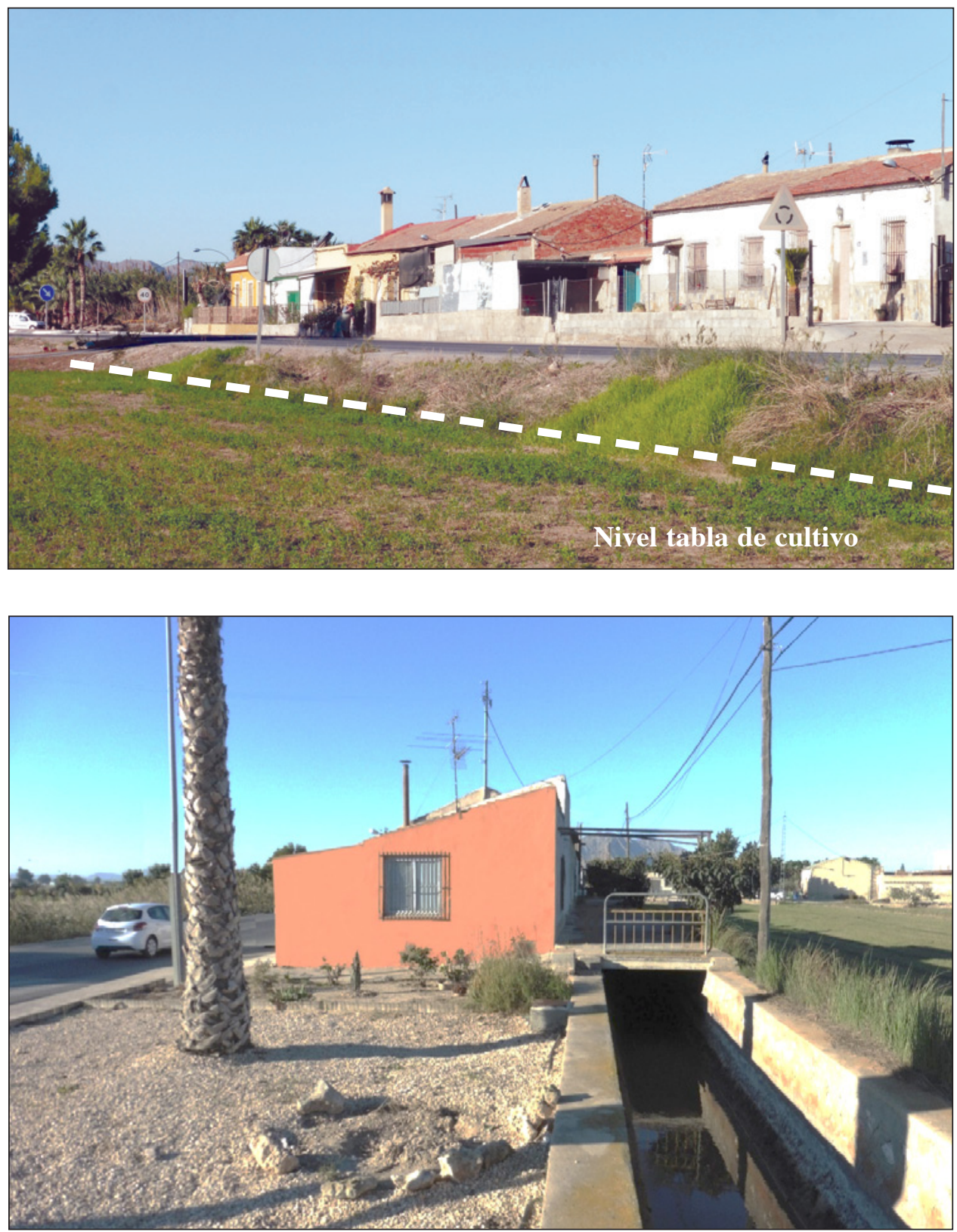

La Barriada de La Cruz se dispone sobreelevada con respecto a las tierras de cultivo al emplazarse sobre la mota de la red de riego, que incorpora a su vez el eje viario (fotografías G. Canales, 2016). 


\section{CATRAL: DEL ANIMUS REGANDI AL ANIMUS AEDIFICANDI}

El término municipal de Catral está situado en el límite noreste de la antigua Huerta de Orihuela, a caballo entre las primigenias tierras transformadas al riego y las redondas de almarjales y saladares del Sinus Ilicitanus. Su demarcación pertenece al llano aluvial del Segura, por lo que la morfología de su territorio se caracteriza por una marcada planitud, al quedar toda su extensión por debajo de los diez metros sobre el nivel del mar. La historiografía siempre ha calificado Catral como una calle de Orihuela, pese a que está situada a quince kilómetros de distancia en dirección al litoral. Esta circunstancia se deriva de la consolidación paulatina de un poblamiento lineal, siguiendo la directriz marcada por la Acequia Mayor de Callosa sobre la franja de suelo que conformaba la mota, al quedar por encima del cauce de riego y las parcelas de cultivo, proporcionando seguridad frente a las periódicas inundaciones del río. Es este uno de los hábitats característicos que estructuran este paisaje agrícola de carácter intensivo, cuyo modelo todavía se puede identificar en la comarca del Bajo Segura.

Esta red de riego es una de las más antiguas de la comarca, tal y como muestra el Libro del Repartiment de las tierras de Orihuela tras la conquista cristiana. Nace del azud de Callosa, en la margen izquierda del río, dentro del casco urbano de Orihuela, del que ya Al-Udri, geógrafo almeriense del siglo XI dejara constancia en su crónica: "Los habitantes de Uryula abren una acequia en este río, que arranca de sus tierras hasta llegar al paraje de Al-katrullat. La longitud y extensión de esta acequia es de 28 millas. Su cauce concluye al sur del paraje, en la región agrícola llamada al-Muwalladin en dirección a la alquería conocida como Al-yuzahira”. Es ésta la canalización más extensa en la parte septentrional de la Huerta, la organización de las tandas o repartos de agua quedaron establecidos a finales del siglo XVI, con derecho cada veinticuatro días para todo el tramo, divididos en tres heredamientos con extensiones de riego diferentes: cuatro días para Orihuela con 4.402 tahúllas; que se elevan a doce para Callosa con una extensión de 17.586 tahúllas; y, finalmente, ocho para Catral con una superficie de 14.544 tahúllas. Desde su origen, el último entandamiento será el más deficitario, al asumir un área de huertas que regar mayor que los tramos previos con menor dotación de tiempo para ello (Roca de Togores, 1832).

Catral se independiza del municipio oriolano a mediados del siglo XVIII, momento clave en la ampliación y consolidación del sistema de riego-avenamiento dominante en la Huerta. Éste fue desarrollado siguiendo las directrices marcadas unas décadas antes por el cardenal Belluga, en el proceso de desecación de la amplia superficie pantanosa existente en su extremo oriental. La inexistencia de elementos físicos de separación entre los cursos inferiores de los ríos Segura y Vinalopó, originaban un espacio continuo, de carácter anfibio, de contacto entre la superficie de almarjales de la marisma del Segura con el Sinus Ilicitanus, espacio endorreico que constituía la desembocadura del Vinalopó. La construcción del Pantano de Elche en el primer tercio del siglo XVII mermó los caudales que alimentaban la laguna ilicitana. Estos hechos alentaron los procesos de bonificación, que repercutieron favorablemente en los territorios colindantes al lograr un descenso en el nivel freático de la zona, circunstancia que benefició a Catral y que está en la base del logro de su autogobierno (Cédula Real, 1741). 
De todo lo anterior se desprenden las dificultades de partida para comprender, tanto la consolidación del poblamiento, como la puesta en cultivo del territorio. De manera que, el punto de inflexión en la mejora de las condiciones de habitabilidad e incremento de la producción, está directamente vinculado al proceso secular de ampliación del regadío, a costa de eliminar el almarjal residual que en ella quedaba, extinguiendo a su vez el endémico foco palúdico resiliente. Es así como en Catral se generalizó el paisaje de Huerta, siendo esta la seña de identidad de la localidad y constituyó, desde entonces el principal medio de vida, si bien no exento de problemas por su ubicación en el extremo final de la Acequia Mayor de Callosa. El patrón escénico que perfiló el carácter local se ha mantenido bastante estable hasta finales del siglo XX, momento en el que irrumpe con fuerza, de manera generalizada en toda la comarca, un nuevo planteamiento socioeconómico, que adquiere aquí una dimensión desproporcionada.

\section{Figura 3}

\section{AZARBE DE LA PARTICIÓN}

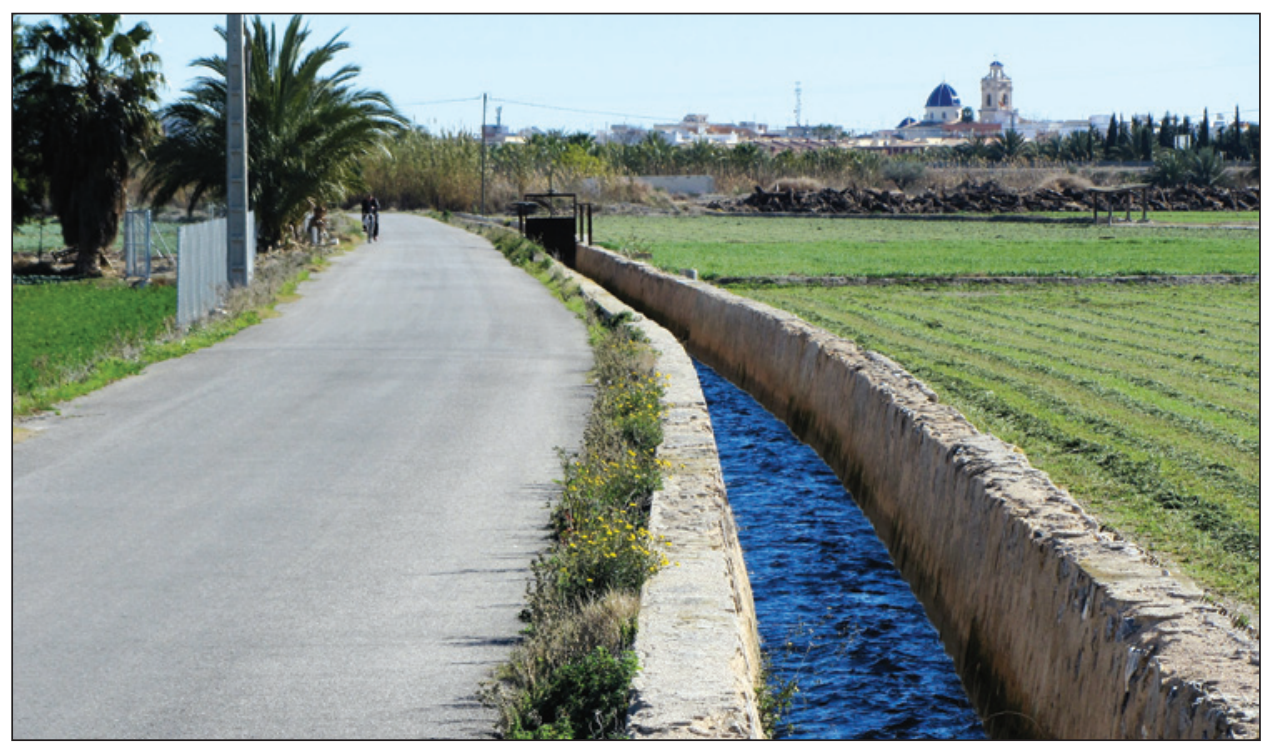

La construcción del Azarbe de la Partición fue obra clave para el saneamiento del territorio en el siglo XVIII, siendo divisoria de términos con las tierras desecadas por Belluga (foto C. García, 2014).

El nuevo panorama está condicionado por factores tanto exógenos como endógenos. Por un lado, la incorporación de España a la Unión Europea incrementó el proceso de masificación de la Costa Blanca como destino turístico internacional que, unido al dinamismo del Arco Mediterráneo, alentó la necesidad de mejorar las infraestructuras viarias existentes y crear otras nuevas. Por otro lado, la devaluación de la agricultura como actividad dominante, derivada del crónico déficit hídrico, la sumió en una profunda crisis; frente a ello, aparecieron nuevas oportunidades en el sector industrial y de servicio, favorecidas 
por las redes de comunicación y transporte. El resultado fue un cambio radical en el uso del suelo, que pasó de ser eminentemente de producción agrícola, a otro de consumo inmobiliario para satisfacer una demanda emergente. La proximidad de la costa, situada a unos quince kilómetros de distancia, convierte este municipio en un foco de atracción en el entorno del Parque Natural de El Hondo, bien conectado al nodo principal de autopistas (A-7, Alicante-Murcia y ramal AP-7, hacia Cartagena), al aeropuerto Alicante-Elche y a la red de ferroviaria de alta velocidad.

El animus regandi fue el principal motor para la transformación paisajística de Catral, de manera que este municipio evidencia la lucha antrópica por imponerse a las condiciones naturales del territorio, por cuanto la secuencia anteriormente descrita almarjales-carrizales-saladares, propia de este entorno, es hoy en día la Huerta de Catral. La demarcación administrativa se apoya sobre todo en los límites artificiales creados por el hombre en el proceso de colonización agraria, esta es mayoritariamente la red de avenamiento, que da salida a las aguas estancadas. Así, el linde noreste sigue el Azarbe de la Partición, fruto del acuerdo con el cardenal Belluga en el saneamiento de tierras de San Felipe Neri, que recibe los caudales salinos que afloran en la base del Cabezo Pardo o de Las Fuentes a través del Azarbe de Los Ojales. El borde sureste queda definido por varios canales de drenaje, como son: el Azarbe de Abanilla, junto con el ramal que sale de éste, denominado Azarbe de Las Cebadas cuyo principal afluente es el Azarbe de la Palmera. Todas estas canalizaciones abastecen el regadío de las Pías Fundaciones de Belluga, cuyos sobrantes confluyen de nuevo en el río Segura a escasos metros de su desembocadura. Mientras que al oeste lo hace con el Brazal del Perpén, que deriva de la Acequia de Callosa, en contacto con la Huerta tradicional de los municipios de Callosa, Orihuela y Almoradí.

Durante siglos, el espíritu que impulsó la transformación de estas tierras al progreso de la agricultura, se enfrentaba permanentemente a la falta de caudales para hacer viable unas producciones competitivas, lo que alentó en las décadas de los años setenta y ochenta del siglo XX la búsqueda de alternativas empresariales de desarrollo centradas, inicialmente, en la fabricación de calzado, dependiente de la actividad económica del valle del Vinalopó (Leal, 1996). Años después, con la crisis industrial, y estando en vigor la Ley Reguladora de la Actividad Urbanística (Generalitat Valenciana, 15 de noviembre de 1994), la reconversión de suelo para uso residencial se impuso como nuevo modelo de crecimiento; circunstancia que produjo un cambio de mentalidad en la sociedad, que vislumbró en el sector de la construcción una estrategia sólida de negocio, que aprovechaba la sinergia del flujo turístico del litoral, y a la vez ofrecía una alternativa residencial de menor coste. De esta manera, la coyuntura social evolucionó a la aparición de lo que hemos denominado animus aedificandi, como reconversión de la economía local hacia el sector terciario, dirigido principalmente a una población extranjera.

\section{LA HUERTA URBANIZADA}

Catral representa, dentro de la Huerta del Segura en su tramo final, un ejemplo paradigmático de la evolución de los aprovechamientos agrarios hacia unas nuevas oportunidades de negocio, que llevan consigo la pérdida de la superficie cultivada. La 
búsqueda de rentabilidad indujo la incorporación de especies agrícolas vinculadas, en principio, a una agricultura comercial. Ésta será sustituida por el desarrollo urbanístico del suelo como motor económico favorecido por su posición ventajosa en el llano aluvial; con una oferta residencial que precede a la demanda real, que ha caracterizado el modelo turístico litoral del sur de la Comunidad Valenciana. Las tres etapas fundamentales que ha conocido este territorio desde su origen almarjalenco comienzan con la transformación en huerta de cultivos herbáceos de ciclo corto, que posibilitan hasta cuatro cosechas anuales en función del tipo de plantación. Este es la imagen identitaria que durante siglos ha marcado el carácter de este valle, condicionado por el acusado estiaje del régimen natural del río que restringía los aprovechamientos durante el periodo estival. La construcción de los pantanos de cabecera en la Cuenca del Segura, surgidos de la necesidad de paliar el efecto destructor de las avenidas anuales, como el de Alfonso XIII (1916) o Talave (1918), a los que siguieron La Cierva (1929) y Fuensanta (1933) y, sobretodo, Cenajo y Fuensanta en 1960, fue el mecanismo que permitió redistribuir los caudales almacenados para la reconversión hacia una huerta arbórea, donde los cítricos -principalmente el limonero- se extendieron por toda la vega. Fue este un cambio paisajístico paulatino donde convivieron la denominada "tierra en blanco", dedicada a los rendimientos herbáceos (cereales, hortalizas, tubérculos e industriales), con la superficie arbolada, generando un tejido productivo mixto.

La última etapa, la de la huerta urbanizada, empieza a gestarse a finales del siglo $\mathrm{XX}$ y se prolonga hasta la primera década de la centuria siguiente. Es en este momento cuando se rompe el equilibrio que históricamente había existido entre los enclaves urbanos y su entorno de regadío. Será el respeto al principal medio de vida y fuente de riqueza, la Huerta, el que determinó la ubicación de cada asentamiento y su forma de desarrollo, buscando siempre la salvaguarda de la inundación y la conservación de la rentable superficie agrícola; pero la irrupción de la crisis de la agricultura minifundista y familiar, junto con la degradación de los suministros hídricos, abrió la puerta al negocio especulativo inmobiliario. Esta transformación se ha materializado a través de diversas pautas de ocupación de suelo que tipificamos en seis modelos diferenciados, divididos en dos bloques, el primero de ellos se corresponde mayoritariamente con las necesidades familiares de la población local sobre modelos de ocupación pre-existentes, mientras que el segundo agrupa aquellas opciones relacionadas con la oferta de viviendas para una población foránea de nueva factura, según las siguientes tipologías:

a) Ampliación urbana planificada: Responde a los crecimientos habituales de los núcleos tradicionales, aunque el ritmo y la extensión de éstos ha sido desproporcionada en relación con la demanda real de la población. En estas nuevas áreas, el uso principal es el residencial, vinculado en muchos casos a otras actividades de carácter comercial o industrial que completan la ordenación pormenorizada del suelo en expansión. Son estas últimas las que protagonizan el frente urbano de los viales que surcan la Huerta, generando un corredor de servicios en origen espontáneo, que se consolidará con el paso del tiempo, hecho que se reproduce miméticamente con bastante frecuencia entre poblaciones vecinas, muy próxi- 
mas, lo que imprime carácter de conurbación a la densa malla de comunicaciones del espacio huertano. Este es el caso de la conexión Almoradí-Dolores.

b) Colmatación del hábitat lineal: Sobre la estructura de aldea-calle existente, únicamente en un lado del camino o red de riego, se da un proceso de densificación, aumento de alturas y ocupación del suelo vacante, unido en un caso a un desdoblamiento de viviendas en el frente opuesto y en otro a un incremento de ocupación parcelaria más allá de la primitiva alineación de casas. Este proceso construye nuevas barreras que ocultan la vista de los espacios agrícolas desde los ejes de tránsito; en ocasiones, son las descuidadas fachadas posteriores las que se contemplan desde otros viales, lo que genera fondos de escena de baja calidad y distorsiona la lectura del paisaje. Un exponente de este cambio lo encontramos en la Vereda de la Buena Vida en Orihuela, que en los últimos treinta años ha pasado de unas permeabilidades visuales que oscilaban del $50 \%$ al $100 \%$ en sus márgenes, a una pérdida de visibilidad en general, siendo extrema en las inmediaciones de la carretera de Beniel con un cierre de la perspectiva a ambos lados.

c) Sustitución del hábitat diseminado: Es un proceso generalizado en toda la Huerta a partir de la pérdida de hegemonía de la agricultura y tras el intenso éxodo rural que se produjo en la segunda mitad del siglo XX. La casa aislada huertana no proporciona los estándares de confort y habitabilidad que hoy día se demanda; lo que ha motivado el abandono y pérdida de estos inmuebles que junto a la vivienda básica disponían de las restantes dependencias vinculadas a la actividad agraria; éstas configuraban un conjunto organizado tanto en estructura abierta como compacta. La pérdida de vigencia aparente de este modelo contrasta con la excepcional ubicación en el territorio que se mantiene, sustituyendo las edificaciones por una arquitectura anodina e impersonal, con ausencia de estilo y que incorpora funciones sobreañadidas a las tradicionales. Estas construcciones salpican todo el llano aluvial, mostrando un amplio catálogo de soluciones y materiales diversos, ajenos a la cultura local, como se pueden observar en la Senda Molina o en la Vereda del Reino entre otros ejemplos.

d) Desarrollo residencial vinculado a campo de golf: Son estas nuevas planificaciones con un modelo importado de solución recreativo-residencial, en la que el deporte ha sido el impulsor de la transformación y el reclamo para atraer a una población extrajera. La recreación de paisajes de climatologías más lluviosas para la definición de las áreas de juego de gran extensión, están apoyadas en conjuntos urbanizados con patrones repetitivos y homogéneos de viviendas similares a los modelos desarrollados en el litoral. Se trata de una artificialización de la naturaleza con pérdida de los elementos que constituyen la base de la identidad huertana. Por lo general, estos nuevos espacios, definidos como proyecto insignia, se encuentran alejados de la cabecera municipal, y presentan una escala de actuación que supera con creces a muchas de las poblaciones ya existentes, produciendo así un urbanismo depredador que no responde a una necesidad social real. La irrupción de la crisis financiera-inmobiliaria ha dejado paralizados muchas de estas iniciativas de negocio (Dolores y Benijófar). 
e) Plan parcial residencial aislado: Los cambios de la legislación urbanística en la Comunidad Valenciana ha propiciado el desarrollo de planes parciales residenciales aislados sobre el parcelario agrícola, utilizando la red viaria tradicional que resulta insuficiente para dar servicio a estos crecimientos. Los proyectos se han basado en la comercialización de la imagen idílica de vivir en una casa en el medio rural aunque sujeta a estándares eminentemente urbanos, posiciones éstas contradictorias que se han promocionado como "turismo rural" o "agroturismo" distorsionando su auténtico significado. Esta opción resulta atractiva para un segmento de turistas interesados en el medio ambiente y el disfrute de espacios de interés ecológico como es la Huerta, frente a la oferta turística de sol y playa; que en cualquier caso permanece por su proximidad a la costa. Iniciativas de estas actuaciones las encontramos en el Barrio Nuevo de La Campaneta (Orihuela), La Monsina (Callosa de Segura), o bien la Urbanización de La Vega (Formentera del Segura).

f) Conjunto residencial en parcela agrícola: A diferencia del tipo anterior, esta nueva forma de ocupación del espacio huertano no obedece a una planificación previa que mantenga las condiciones de urbanización, zonas verdes y provisión de suelo para dotaciones públicas como establece la normativa urbanística vigente. La distribución y subdivisión de parcelas se realiza a partir de los caminos de la vega ya existentes, apropiándose del uso para acceso a las propiedades, pero sin la ejecución de aceras o alumbrado público. Se generan así bolsas de suelo transformado, con una geometría que responde a los lindes de las fincas matrices y que se distribuyen por todo el territorio de manera caprichosa, tanto por su tamaño, perímetro, ubicación y número de viviendas que concentran. En el término municipal de Catral se ha extendido esta práctica de forma dominante, lo que nos proporciona un ejemplo paradigmático para la reflexión sobre los procesos de transformación del hábitat en la Huerta del Segura.

\section{CATRAL, ATOMIZACIÓN URBANA DE LA HUERTA}

Respecto a la relación de formas de ocupación de suelo en la Huerta anteriormente señaladas, Catral participa de las siguientes tipologías en su territorio: la más frecuente y natural en el crecimiento de una población es la que tiene que ver con la ampliación urbana planificada, mediante la aparición de ensanches que desarrollan el conjunto vecinal con manzanas compactas, conformadas por edificaciones alineadas a calle y levantadas entre medianeras, partiendo del núcleo fundacional entorno a la iglesia; simultáneamente, se ha producido una colmatación del hábitat lineal que dio origen a la localidad y que abarca desde el Barrio de la Cruz hasta el de Santa Águeda con el apéndice rectilíneo de El Santiel; más allá de estos frentes urbanos, cuyo desarrollo mantiene la lógica de consolidación del urbanismo tradicional, se ha producido un fenómeno reciente de invasión dispersa por la superficie huertana periférica, formando conjuntos residenciales en parcelas agrícolas. Es este proceso de expansión del hábitat el que convierte a Catral en el exponente de otra manera de operar sobre el terreno, tanto por sus características específicas, como por la gran extensión que ocupa. En efecto, si tomamos como referencia la superficie total del municipio -1.980 ha- comprobamos 
que el suelo urbanizado en 2011 supone más del 20\% de la misma, del que un 13\%, es decir 262 ha, corresponde al nuevo patrón de asentamiento, disperso y aleatorio, que ha surgido en las últimas décadas y que paralizó la administración autonómica en el año 2007. Momento en que le fueron retiradas las competencias urbanísticas al consistorio, a raíz de la manifiesta dejación de funciones en la aplicación de la legislación vigente. La consecuencia de esta permisividad y connivencia político-empresarial deja como resultado una Huerta colonizada por grupos de viviendas aisladas que complican la gestión territorial.

En la Tabla 1 se analizan pormenorizadamente la distribución del suelo urbanizado en el municipio de Catral por superficies y usos según los datos extraídos del Sistema de Información de Ocupación del Suelo en España (SIOSE) correspondientes a 2011. La información está estructurada en tres bloques: suelo urbano, residencial en parcela agrícola y, por último, industrial-comercial. El primero corresponde al núcleo compacto con tres áreas homogéneas de tejido urbano consolidado y claramente diferenciadas, que se identifican con las formas de crecimiento tradicional: el asentamiento primigenio y sus extensiones lineales, las citadas aldeas-calle, ocupan un $20 \%$ de la trama urbana con un reparto equilibrado; mientras que las zonas de ensanche planificado es el $80 \%$ del callejero restante. Estas ampliaciones contemporáneas que ocupan terrenos fértiles del llano aluvial, rompen la práctica ancestral que se limitaba a colonizar las áreas sobre micro-elevaciones que siguen la red caminera, con la finalidad de protegerse de las riadas del Segura.

El segundo bloque, es decir, el suelo residencial en parcela agrícola, supone la más reciente expansión dispersa por el término de Catral, a la vez que es la que ocupa mayor espacio, ya que cuadruplica la superficie del suelo urbano del municipio. Tipológicamente se introduce la vivienda unifamiliar aislada sobre suelo rural, que incorpora elementos de urbanización propios de una segunda residencia, como son piscina, acondicionamiento interior del suelo con áreas pavimentadas o cubiertas de grava, jardinería ornamental y mobiliario urbano, todo ello dentro de un recinto vallado perimetralmente con muros de fábrica. Una consecuencia colateral de este modelo es la necesidad de mejorar los accesos a las parcelas, ensanchando los viales mediante el entubado de los canales de riego y avenamiento, además de modificar la superficie de rodadura. Estas soluciones producen un alto nivel de impacto visual y ambiental, amén de una imagen adulterada del paisaje de Huerta secular, en el que la superficie destinada a cultivo es testimonial, tal y como se puede ver en la tabla de referencia.

El tercer y último bloque recoge los datos relativos al suelo industrial-comercial, en el que se ha seguido la misma clasificación tipológica en función de la ubicación y organización de la industria en parcela con el fin de contraponer dos modelos: el clásico en manzana cerrada frente a los recientes desarrollos de carácter aislado, emplazados en terreno agrícola. El polígono Alfalfar es un proyecto ex-novo y planificado, desarrollado junto al núcleo urbano apoyado a ambos lados de la carretera CV-8630 que lo conecta con el eje industrial del Vinalopó. En la actualidad se ha mejorado su accesibilidad territorial con un enlace directo a la AP-7 en un tramo libre de peaje, que facilita la conexión con el Corredor Mediterráneo y la Autovía de Levante (A-31) hacia Madrid. Al igual que ocurre en la dispersión del hábitat residencial, se detecta un paralelismo en relación al uso 


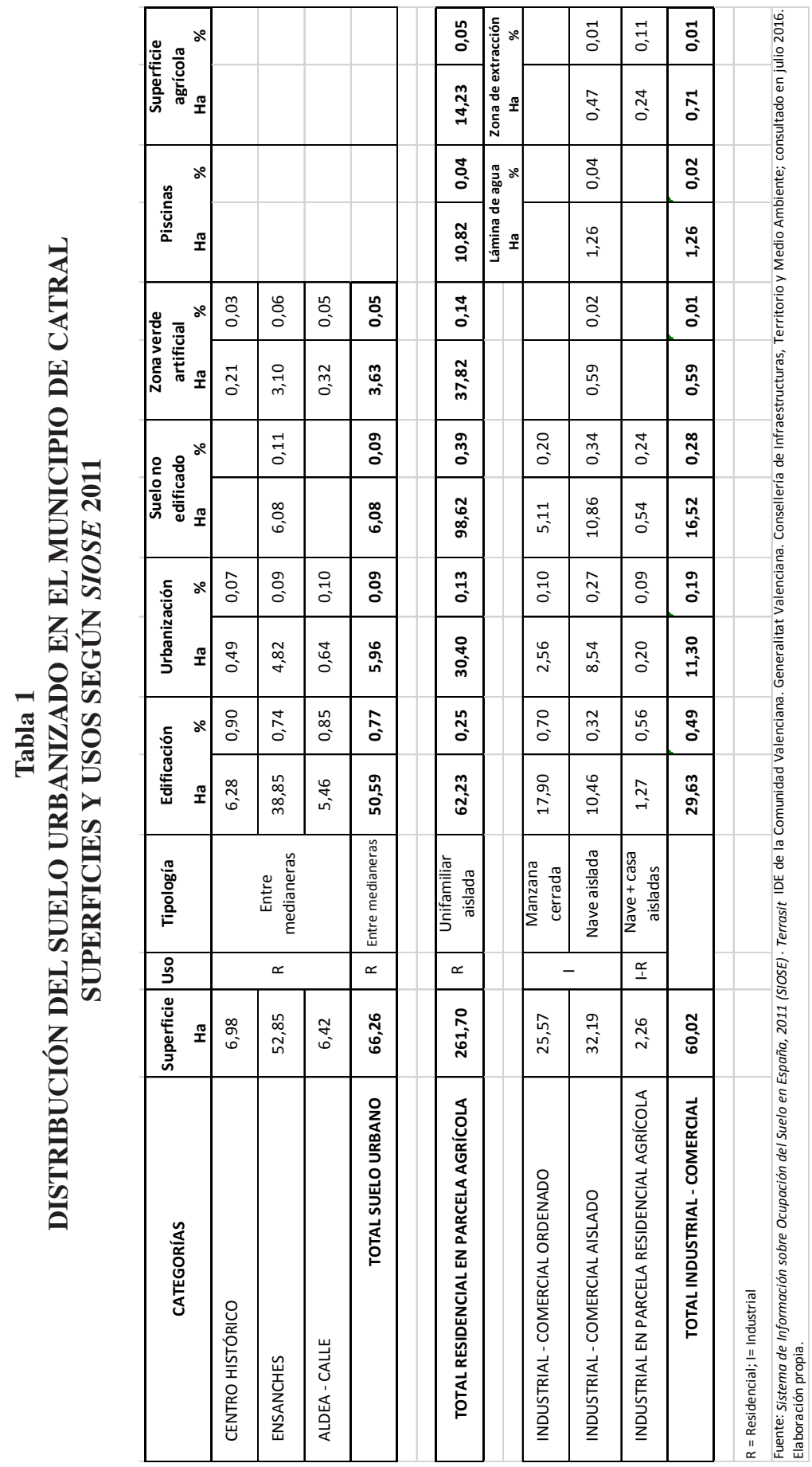


industrial-comercial, de manera mayoritaria en nave aislada, pero también como conjunto en parcela vallada de edificación destinada tanto a residencia particular como a negocio familiar. Si atendemos a la superficie afectada de estos tipos, el primero representa el $43 \%$ del uso industrial proyectado, mientras que el resto supone el $57 \%$ en un modelo disgregado no regulado. El acceso a la red de carreteras se realiza a costa de la transformación del entramado viario propio de la Huerta, cuyas veredas están concebidas desde la estructuración de la red de riego-avenamiento y de la propiedad de la tierra, de trazado irregular y anchura variable, con los inconvenientes que ello supone para una actividad ajena a los valores del territorio en el que se implanta.

Esta configuración atomizada del suelo municipal de Catral genera una ruptura del paisaje tradicional del último tramo del río Segura. Desaparece así la división ruralurbana para dar paso a una realidad diferente, en la que se fragmenta el espacio agrícola con la aparición diseminada de suelo artificializado de carácter residencial o industrial. El modelo actual supone un elevado impacto de carácter medioambiental desde diferentes perspectivas, que transmite la imagen de un enclave desorganizado, derivado de la falta de planificación del proceso de ocupación. La consecuencia de esta dinámica espontánea de transformación del medio, representa un nuevo paradigma que impone cambios estructurales en los elementos funcionales del paisaje huertano, como son: la obligada mejora de la red de caminos -ensanchamiento mediante el entubado de la red de riego- avenamiento adyacente y el asfaltado de la superficie de rodadura -impermeabilizando el drenaje natural del terreno-; la prolongación de las redes básicas de servicios urbanos -como mínimo agua potable y electricidad-, junto al incremento de determinados servicios municipales (recogida de residuos, seguridad), y ante la imposibilidad de dar una solución óptima a la red de saneamiento por la complejidad y dispersión del hábitat construido, han proliferado las fosas sépticas; la pérdida de visibilidad de la superficie cultivada debido a la delimitación de las propiedades con cerramientos opacos de obra con una altura que interfiere en la percepción visual del entorno desde los recorridos de tránsito habitual.

La metamorfosis experimentada por Catral, a escala reducida y en un contexto rural, es similar a la que conocen los grandes espacios metropolitanos, cuyas periferias urbanas y bordes de grandes infraestructuras de comunicación -autopistas- en los que aparecen espacios indeterminados, con límites imprecisos, de usos inciertos y expectantes, ambiguos, que como señala Joan Nogué son "una mezcla entre lo que han dejado de ser y lo que no se sabe si serán" (Nogué, 2007). Estas circunstancias conllevan a una compleja legibilidad del territorio, al aparecer fracturado y desdibujado, de morfología repetitiva, como copia de los modelos desarrollados en la costa. Esta amalgama de usos residenciales, industriales y comerciales, dejan espacios intersticiales yermos, fruto del abandono de la actividad agraria, en espera de una mayor rentabilidad, sin solución global de continuidad o configuración organizada de nuevas centralidades urbanas; donde se alternan viviendas dispersas, invernaderos, vertederos incontrolados, naves industriales, entre otros, cuya anarquía dentro del medio rural incide en la desafección de los lugareños y en la pérdida de una identidad fraguada a lo largo de siglos. 


\section{Figura 4 \\ SUSTITUCIÓN DEL HÁBITAT TRADICIONAL}
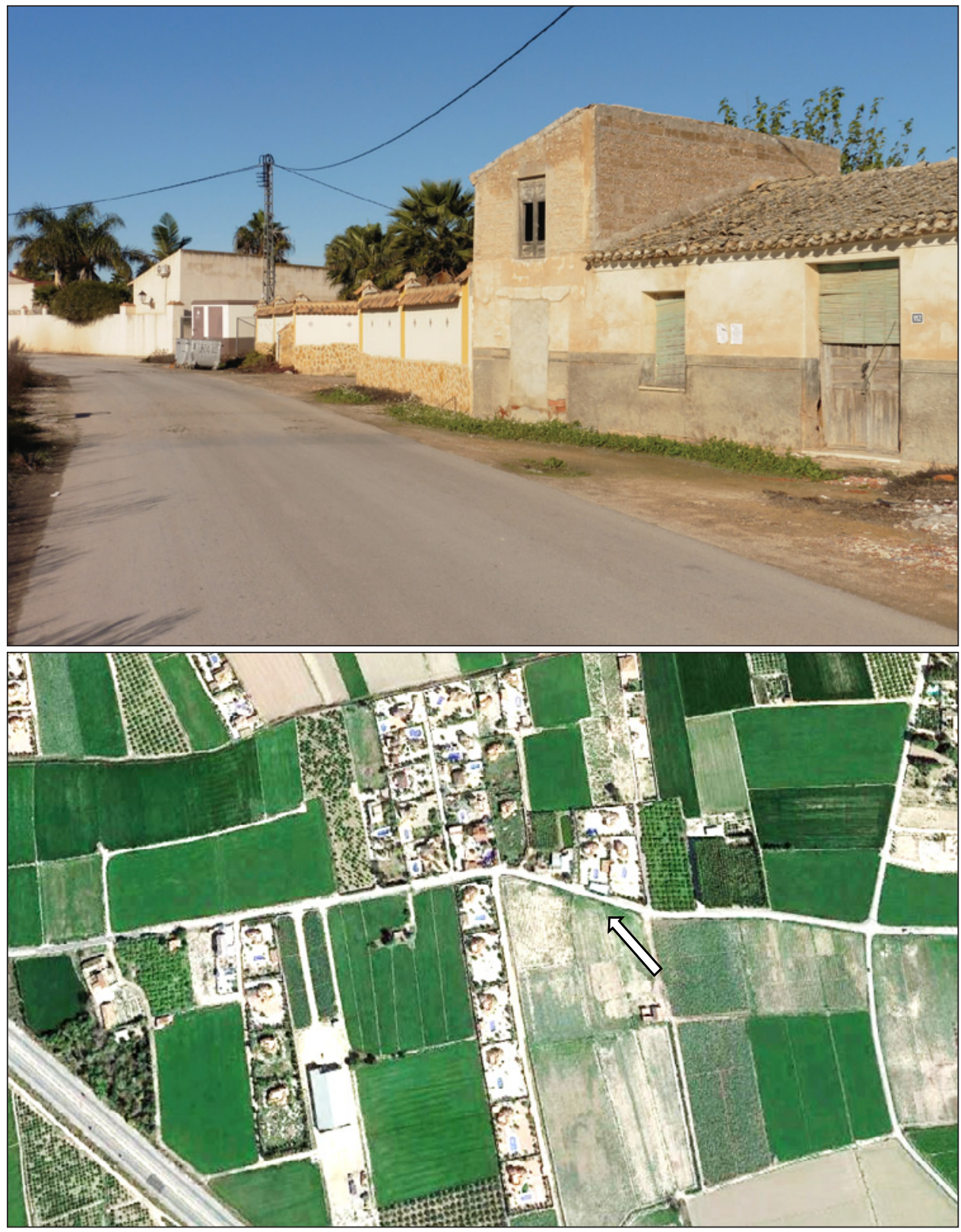

Camino de Hornos. Contraposición de tipologías residenciales en la Huerta: la vivienda tradicional, en primer plano de la foto superior, se abre a la Huerta; mientras que las nuevas ocupaciones se cierran al espacio agrícola. Fuente: fotografía G. Canales (2016) y Google Earth (marzo, 2015). 


\section{Figura 5 \\ DISTORSIÓN VISUAL DE LA HUERTA}

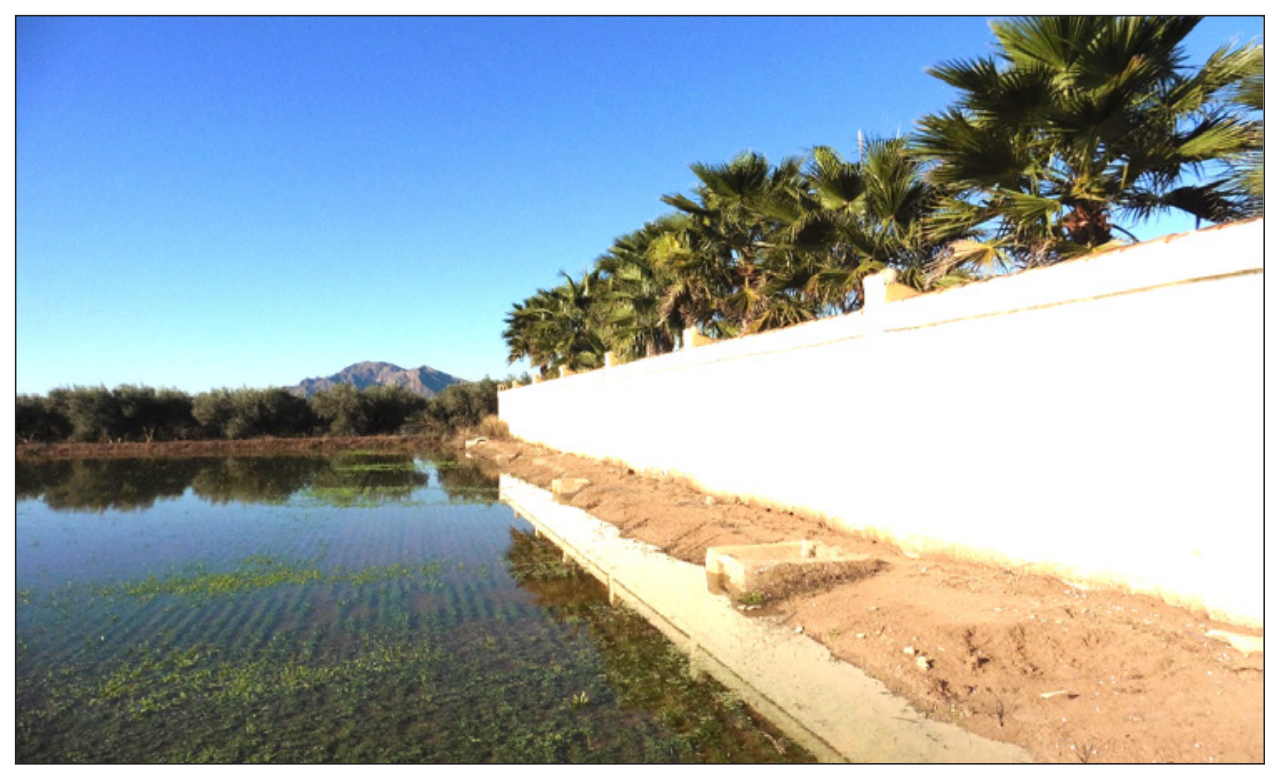

El modelo actual de ocupación del espacio genera una ruptura evidente en la percepción del paisaje de Huerta con un elevado impacto medioambiental (fotografía C. García, 2016).

La génesis de los cambios ocurridos en la vega de Catral se propiciaron por la conjunción de una serie de factores de diverso tipo: legislativo, con la modificación de la superficie mínima de parcela para construcción en el medio rural, que se rebajó de los $10.000 \mathrm{~m}^{2}$ a la mitad, siempre que el ayuntamiento lo solicitara alegando la proximidad a asentamientos con servicios mínimos consolidados como los que se dan en las barriadas lineales de las aldeas-calle; social, donde la aparición del turismo residencial generan oportunidades de negocio en un suelo de baja rentabilidad agrícola debido al déficit hídrico que soportan sus tierras en la cola de todo el sistema de riego; municipal, en el que hay una dejación de funciones en el control de la construcción, con la inoperancia de las brigadas de disciplina urbanística del consistorio, donde en virtud de los plazos de caducidad de la infracción correspondiente, apoyándose en los resquicios burocráticos, facilitar la legalización posterior de una situación irregular; registral, con la legitimación de la transformación del suelo, mediante su inscripción en el Registro de la Propiedad, al no constar prevención alguna e ir avalada por el correspondiente certificado profesional de antigüedad de la obra; coyuntural, con la connivencia de todos los agentes implicados en el trámite, en el que la secuenciación de varios silencios administrativos junto con la prescripción de las infracciones urbanísticas favorecen el cambio de uso dentro de la parcela agrícola, donde el cercado perimetral sirve para llevar a cabo una división horizontal de las diversas viviendas unifamiliares que en ellas se levantan, sobre una superficie de carácter comunitario, regulada por un derecho de copropiedad, originando complejos inmobiliarios privados. 


\section{Figura 6 \\ IMPACTO DEL CAMBIO DE MODELO PRODUCTIVO}

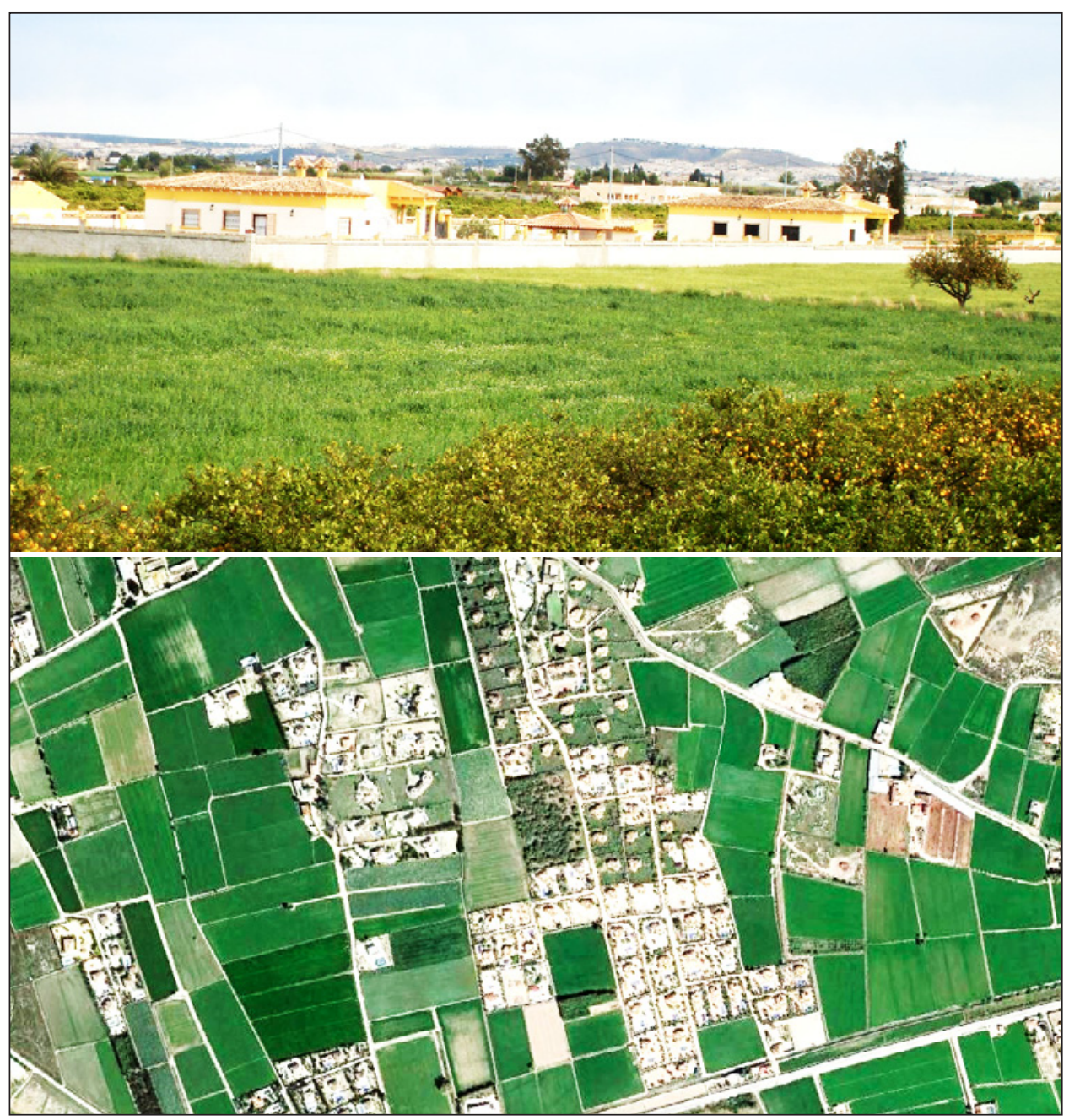

Área de Huerta entre el Azarbe de la Palmera y el Camino del Hondo. Fragmentación de la homogeneidad del tejido agrícola con la aparición diseminada de suelo artificializado de carácter residencial o industrial. Fuente: fotografía G. Canales (2016) y Google Earth (marzo, 2015).

El desarrollo de este proceso coincide en el tiempo con iniciativas de desarrollo y diversificación económica de zonas rurales bajo el auspicio del programa PRODER. Las líneas de actuación estaban perfectamente definidas tomando como base la especificidades del territorio, cuyo objetivo principal era el desarrollo endógeno atendiendo a criterios de sostenibilidad, buscando el mantenimiento de la población, elevando las rentas y el bienestar social de sus habitantes, además de asegurar la conservación del espacio y de los 
recursos naturales. Para ello se definieron cuatro líneas de actuación, siendo una de ellas la creación de servicios turísticos en las poblaciones del entorno donde se prestaba especial atención al turismo de proximidad y corta duración, así como al agroturismo. Si bien, la realidad ha sido otra, pues se ha desvirtuado el planteamiento original y el desarrollo turístico sostenible es una entelequia: por un lado, en relación con los establecimientos inscritos como casas rurales se ha pasado de dos a cinco entre 2009 a 2015, lo que supone un número de plazas ofertadas que ha evolucionado de 18 plazas a 38 respectivamente, según datos de la Generalitat Valenciana; por otro lado, conforman el censo local de residentes extranjeros 2.952 habitantes, correspondientes a 54 nacionalidades distintas, que representan el 31,19\% sobre una población total de 9.466 personas según el censo de población de 2011.

\section{CONCLUSIONES}

Catral es un caso extremo pero representativo de una situación que se repite en todo el espacio agrario tradicional de la Huerta del Segura. El proceso ha sido ampliamente debatido y estudiado en las áreas metropolitanas de las dos grandes urbes, capitales autonómicas con Huerta, los casos de Valencia y Murcia y, en menor medida, de Orihuela, fruto de las transformaciones y crecimientos propios de estos centros dinámicos de escala supramunicipal. La singularidad del municipio analizado radica, no sólo en los cambios descritos en su territorio, sino en la escala desproporcionada que los mismos alcanzan, en relación a la superficie total y a la población que allí reside.

Este espacio agrario, surgido de la lucha secular de sus habitantes frente a las adversas condiciones medioambientales propias del llano aluvial donde se asienta, con la reducción paulatina de los terrenos de almarjal hasta dejarlos acantonados en el límite con el Parque Natural de El Hondo, linde noreste de su demarcación, que contribuye a aumentar la belleza y singularidad de su paisaje. Territorio con un sistema de agro-biodiversidad muy variado, siendo una de las zonas más valiosas desde el punto de vista paisajístico, por su naturaleza, por sus valores ambientales, así como por la riqueza patrimonial y agrícola que alberga, siendo un ejemplo de transformación sostenible. La Huerta constituye, por tanto, una creación artificial que ha propiciado durante siglos un alto rendimiento agrícola de primer orden sin dar pruebas evidentes de agotamiento de sus suelos, cuya fortaleza ha radicado en un funcionamiento integral de carácter global.

El cambio de modelo productivo y el abandono de los cultivos han generado un aumento de la fragilidad del sistema, al desestructurar las redes funcionales básicas que constituyen este paisaje, a la par que introduce obstáculos físicos y visuales que fragmentan la percepción. Catral es un ejemplo paradigmático de la alteración y distorsión escénica que puede llegar a sufrir un paisaje con el desarrollo de nuevos patrones socioeconómicos, ajenos a la dinámica histórica del lugar. El frágil equilibrio productivo que tantos esfuerzos necesitó desde el trabajo comunitario para implantar el regadío en un medio hostil -de carácter semipantanoso- cede ante el abandono y la fuerza de la naturaleza vuelve a recolonizar el espacio de antaño. El paisaje antropizado de Huerta sucumbe y se desvanece, de manera inadvertida para una población que ha perdido el vínculo afectivo con el medio. 


\section{Figura 7 \\ ARTIFICIALIZACIÓN DEL PAISAJE DE HUERTA}
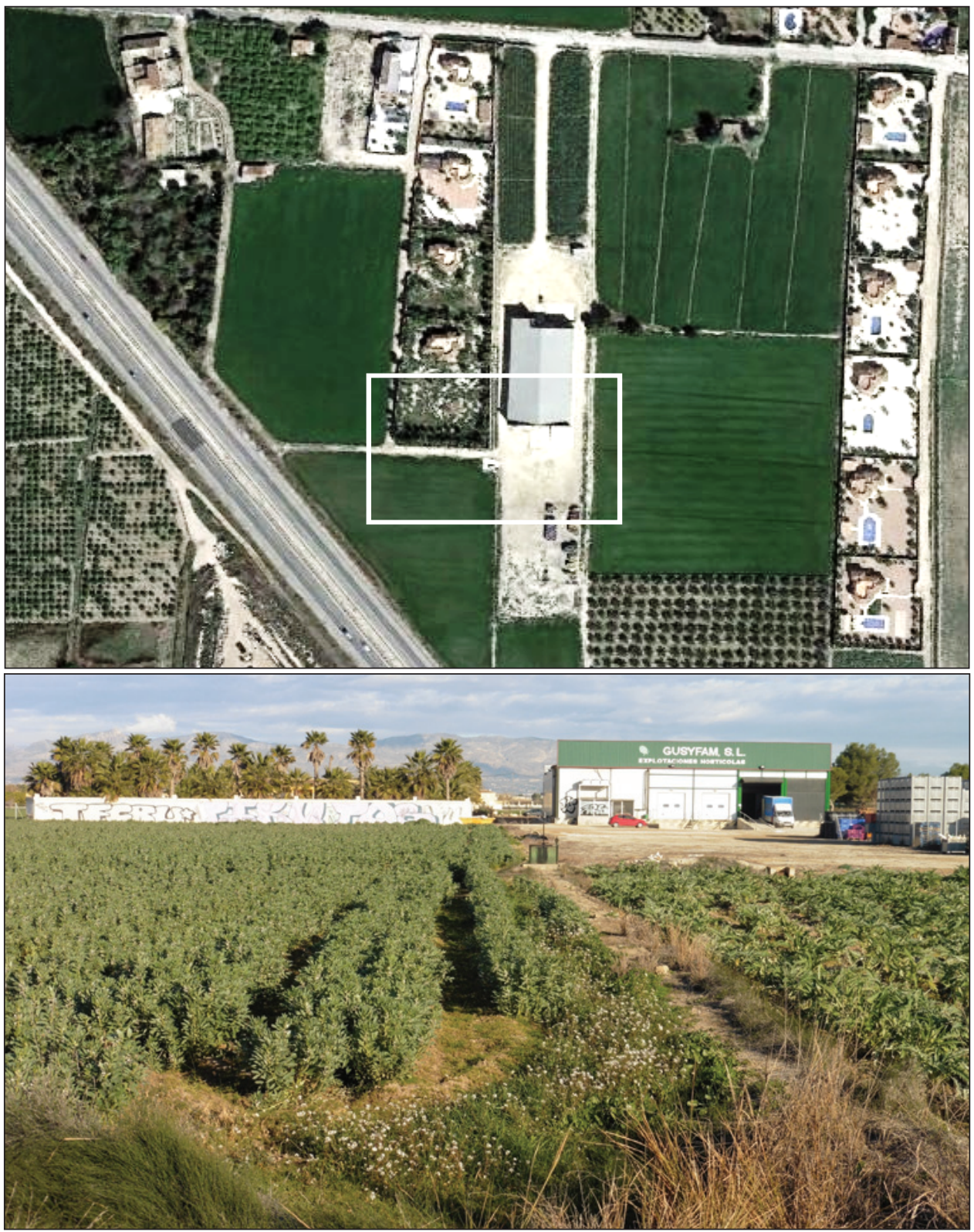

Las imágenes sintetizan el proceso de cambio sufrido en el paisaje huertano, cuyo impacto se concreta en: el entubamiento de la red de riego deja como única señal visible el partidor; la nave comercial con explanación perimetral; el vallado de cierre de parcela residencial que alberga varias viviendas, en el que los grafitis incrementan el grado de distorsión escénica. Fuente: fotografía G. Canales (2016) y Google Earth (marzo, 2015). 
Todo este proceso, que tiene un elevado impacto sobre el hábitat, se ha visto acentuado por la dispersión en el tradicional minifundio huertano de micro-parcelas artificializadas que: primero levantaron la construcción de carácter residencial o industrial en una tabla de huerta; luego vallaron y adecuaron la superficie exterior no afectada por la edificación; para terminar, por último, demandando los servicios urbanos. Esta improvisada urbanización se desarrolla con una dinámica opuesta a la práctica tradicional de producción de suelo urbano, lo que lleva a la necesidad de extender en malla todas las infraestructuras sin una planificación pautada, hipotecando cualquier intento de regeneración del espacio agrario en el futuro. La carencia de un objetivo común y consensuado en la estrategia territorial, ha llevado a que se consolide la ocupación diseminada del suelo tal y como ha sido descrito. Al contrario de lo ocurrido en el proceso fundacional, cuando todos los agentes implicados tenían un propósito bien definido, que se concretó en la construcción del paisaje de Huerta, identidad secular de este valle; en la coyuntura actual, los actores intervinientes -administración, empresarios, propietarios y población local en generalhan operado de forma parcial y descoordinada, sin ejercer ninguna responsabilidad social corporativa en la búsqueda de soluciones para lograr un equilibro entre economía, sociedad y medioambiente, como motor de desarrollo que preserve los valores singulares y funcionales específicos en este territorio.

\section{BIBLIOGRAFÍA}

CANALES MARTÍNEZ, G. y DE JUANES RODRIGUEZ, F. (2016): Memorial San Isidro. Transformación territorial y génesis de San Isidro (Alicante). Universidad de Alicante, Ayuntamiento de San Isidro, 96 pp.

CANALES MARTÍNEZ, G. y LÒPEZ POMARES, A. (2012): "El desarrollo turístico de Orihuela y su incidencia en el poblamiento (1910-2010)", Cuadernos de Turismo, n. ${ }^{\circ}$ 29, pp. 109-135.

CASADO DIAZ, M.A. (1999): "Socio-demographic impacts of residential tourism: a case of Torrevieja, Spain”, International Journal of Tourism Research, Vol. I, n. . 4, pp. 223-237.

CÉDULA REAL (1741): Cédula Real por la que Felipe V otorga a Catral el privilegio de Villa Real, en Aranjuez a 14 de Mayo de 1741 (edición facsímil), Castrum Altum, $\mathrm{n},{ }^{\circ}$ 5, Revista cultural de la Asociación de Investigadores Locales de Catral, 2011, $54 \mathrm{pp}$.

FERNÁNDEZ NAVARRETE, D. (2005): "La política económica exterior del franquismo: del aislamiento a la apertura", Revista Historia Económica, n. . 30, pp. 49-78.

GARCÍA MAYOR, C. y CANALES MARTÍNEZ, G. (2015): La Huerta de Orihuela en el Bajo Segura. Elementos funcionales en la construcción del paisaje. Alicante, Universidad de Alicante, 66 pp.

GENERALITAT VALENCIANA, (2009 y 2015): Oferta Turística Municipal y Comarcal de la Comunidad Valenciana. Agencia Valenciana de Turismo. Registro de Empresas Turísticas.

LEAL GÓMEZ, F.M. (1996): "La industria en el medio rural: Catral 1950-1990”, Alquibla, Revista de Investigación del Bajo Segura, n. ${ }^{\circ}$ 2, pp. 215-239. 
MINISTERIO DE FOMENTO (2011): Sistema de Información de Ocupación del Suelo en España (SIOSE). Plan Nacional de Observación del Territorio. Instituto Geográfico Nacional. (www.siose.es). También en Terrasit IDE de la Comunidad Valenciana. Generalitat Valenciana. Consellería de Infraestructuras, Territorio y Medio Ambiente; consultado en julio 2016 (www.terrasit.gva.es).

NOGUÉ, J. (2007): “Territorio sin discurso, paisaje sin imaginario. Retos y dilemas", Ería, n. ${ }^{\circ}$ 73-74, pp. 373-382.

ROCA DE TOGORES Y ALBURQUERQUE, J. (1832): Memoria sobre los riegos de la huerta de Orihuela. Valencia, Oficina de D. Benito Monfort, pp. 40-46.

VERA REBOLLO, F. (1984): "Mutaciones espaciales producidas por el turismo en el municipio de Torrevieja", Investigaciones Geográficas, n. . 2, pp. 115-138. 
